\title{
Do farm-grown lungs breathe better?
}

\author{
Jon Genuneit, ${ }^{1}$ Erika von Mutius ${ }^{2}$
}

In Thorax, Campbell et al ${ }^{1}$ report an association of growing up on a farm with better adult lung function. On closer investigation, this effect was confined to the $\mathrm{FEV}_{1}$ in female participants in the study. A novel finding and a paper worth reading-but what may be harder to glean is its relevance and implication for future research.

The 'farm-effect' on allergic disease has been well established in numerous studies. Recent systematic reviews with meta-analyses show a strong protective effect of growing up on a farm on childhood atopy ${ }^{2}$ and a lesser effect on childhood asthma. ${ }^{3}$ In these meta-analyses, the effect estimates for the 'farm-effect' on asthma were much more heterogeneous than those on any atopic sensitisation. ${ }^{2} 3$ This may be driven by the mix of different farm exposures shown to be important. ${ }^{4}$ It has also been suggested that the increased heterogeneity in estimates of the 'farm-effect' on asthma is partly driven by the mix of asthma phenotypes in the respective studies. ${ }^{3}$

Indeed, the present study by Campbell et al is one of the few studies presenting results completely stratified by atopy to investigate this further. Here, the authors conclude that protective effects on atopic asthma, atopic bronchial hyperresponsiveness (BHR) and atopic nasal symptoms in comparison to non-atopic subjects without asthma, BHR and nasal symptoms, respectively, exist. On closer investigation of the presented data, these associations are fully driven by the 'farm effect' on atopy. No separate 'farm-effect' on asthma, BHR or nasal symptoms shows up when comparing diseased with non-diseased separately within the two strata of atopic and non-atopic subjects. It has been previously shown that effect estimates for atopic asthma depend on the choice of the reference group in case of strong overall effects on atopy. ${ }^{5}$ It is remarkable that early life exposure to farming environments has sustained

\footnotetext{
${ }^{1}$ Institute of Epidemiology and Medical Biometry, Ulm University, Ulm, Germany; ${ }^{2}$ Dr. von Hauner Children's Hospital, Ludwig Maximilians University Munich, Munich, Germany

Correspondence to Dr Jon Genuneit, Institute of Epidemiology and Medical Biometry, Ulm University, Helmholtzstr. 22, Ulm D89081, Germany; jon.genuneit@uni-ulm.de
}

effects on adult atopic sensitisation. However, added effects on asthma, BHR and nasal symptoms as suggested by previous studies in childhood ${ }^{6}$ and adulthood ${ }^{7}$ are not supported by the present study. ${ }^{1}$

The result of a 'farm-effect' on lung function has been investigated to a lesser extent, and direct comparison with previous studies is hindered by differing scaling of the lung function parameters. Higher $\mathrm{FEV}_{1} / \mathrm{FVC}$ values among those growing up on a farm have been found in one previous study among atopic children only ${ }^{6}$ but not in two other studies among all children. ${ }^{89}$ The association in the present study was attenuated after further adjustment, including adjustment for parental smoking, but no stratification for atopy was presented. Personal smoking did not seem to confound the association but residual confounding due to crude measures of smoking history cannot be excluded. The stronger association with higher $\mathrm{FEV}_{1}$ in the present study was more apparent in women and varied across participating centres. Such an isolated lung function parameter is hard to interpret in the absence of findings for FVC and the $\mathrm{FEV}_{1} / \mathrm{FVC}$ ratio, as $\mathrm{FEV}_{1}$ can represent lung volume and airway obstruction. Whether the on-average $110 \mathrm{~mL}$ higher $\mathrm{FEV}_{1}$ in women who grew up on a farm can be replicated in other studies, whether this effect persists after accounting for atopy, and whether it is clinically meaningful remains, thus, to be elucidated.

What may be more interesting in this context is the sex-specificity of the 'farmeffect'. A stronger effect on women has been previously shown among adults ${ }^{10-12}$ as well as children and adolescents, ${ }^{8} 1314$ although it has been reversed, ${ }^{15}$ absent or only marginally statistically significant in the data of other studies. ${ }^{16} 17$ The sexspecificity may point towards (1) unaccounted-for disease heterogeneity between women and men, (2) differing exposure to farming environments, including occupational exposure in adult life but also other exposure in early life, (3) differing confounding lifestyle factors, such as smoking and (4) differing physiological, hormonal or growth characteristics affecting lung physiology. Whereas personal smoking, body weight and body height have been adjusted for in the present study, other proposed factors remain as possible explanations. Age at onset of asthma may also play a role since one report on childhood and adolescence has shown that sex-specific associations of exposure to farming with asthma are age-dependent. ${ }^{14}$

Of note, the study population in the present study covers a wide age range. Although age is adjusted for, previous publications, including another one also using European Community Respiratory Health Survey (ECRHS) data, have indicated cohort effects. ${ }^{18}{ }^{19}$ Cohort effects may exist if the mode of farming changed over time, for example, farms were recently only run part-time which attenuates the effect. ${ }^{20} 21$ Moreover, no information on age at onset of atopy or atopic asthma is shown. The 'farm-effect' documented in the present study may be a sustained effect from childhood onwards. Alternatively, it may be an effect on lateronset atopy or atopic asthma, as indicated by data from the RHINE study which includes part of the ECRHS study population. ${ }^{12}$ Arguably, a substantial portion of adult-onset or late-onset disease may be misclassified due to lack of recall of childhood disease in mid-adult ages.

While critics may argue for alternative explanations of the 'farm-effect' (eg, genetics, access to or utilisation of healthcare), its environmental component seems established beyond reasonable doubt. One good example is the dramatic increase of atopy in a rural region of Poland accompanied by a decrease of exposure to farming during the same time. ${ }^{22}$ Another prominent example is the exploitation of two populations, the Amish and the Hutterites. ${ }^{23}$ In this comparison, the model of exposure to farming environments is distilled to its environmental core.

Not all protection from atopy relates to farming in this study. Campbell et $a l^{1}$ also define a 'biodiversity score' based on childhood exposure to cats, dogs, day care, bedroom-sharing and older siblings. One might argue that the aforementioned factors are proxies for other than microbial exposures and that the simple dichotomisation and assumed additive effects are not the optimal operationalisation. Moreover, upbringing in a village also shows some protection, but it remains unclear whether this effect is to some extend attributable to the 'biodiversity score'. Possibly, the effect of such a score is only discernible in innercity environments where other outdoor exposures (eg, greenness) are lacking. Nonetheless, the analyses show that the protective 'farm-effect' is stronger than what individuals brought up in inner cities can experience by exposure to pets, day care and siblings. Also, given that these 
exposures are probably as difficult to intervene on as is the place of upbringing, we should consider keeping on searching for the most important environmental exposures underlying the farm-effect for future preventive efforts.

So, do farm-grown lungs breathe better? The present study does not add much to answer this question. But in addition to all the previous evidence, it is another reminder from a large-scale study that effects of childhood exposure to farming environments on atopy and thereby atopic disease may well extend into adulthood. This makes the mechanisms underlying the 'farm-effect' particularly important for future preventive efforts. How shall we proceed? Exploring disease heterogeneity and sub-phenotypes including age at onset as well as investigating sex-specificity should be added to the investigative toolbox. In addition, making use of model populations may be promising in future efforts to unravel elements in the mix of exposures or pathophysiological mechanisms that are associated with growing up on a farm.

Contributors JG and EvM drafted this manuscript together and both approved the final version.

Competing interests None declared.

Provenance and peer review Commissioned; externally peer reviewed.

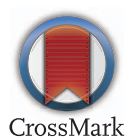

To cite Genuneit J, von Mutius E. Thorax 2017;72:202-203.

Received 12 September 2016

Revised 8 November 2016

Accepted 9 November 2016

Published Online First 2 December 2016

\section{(n) Linked}

http://dx.doi.org/10.1136/thoraxjnl-2015-208154

Thorax 2017:72:202-203.

doi:10.1136/thoraxjnl-2016-209280

\section{REFERENCES}

1 Campbell B, Raherison C, Lodge CJ, et al. The effects of growing up on a farm on adult lung function and allergic phenotypes: an international population-based study. Thorax 2017;72:236-44.

2 Campbell BE, Lodge CJ, Lowe AJ, et al. Exposure to "farming" and objective markers of atopy: a systematic review and meta-analysis. Clin Exp Allergy 2015;45:744-57.

3 Genuneit J. Exposure to farming environments in childhood and asthma and wheeze in rural populations: a systematic review with meta-analysis. Pediatr Allergy Immunol 2012:23:509-18.

4 Ege MJ, Frei R, Bieli C, et al. Not all farming environments protect against the development of asthma and wheeze in children. J Allergy Clin Immunol 2007;119:1140-7.

5 Pekkanen J, Lampi J, Genuneit J, et al. Analyzing atopic and non-atopic asthma. Eur J Epidemiol 2012:27:281-6.

6 Fuchs 0 , Genuneit J, Latzin $\mathrm{P}$, et al. Farming environments and childhood atopy, wheeze, lung function, and exhaled nitric oxide. J Allergy Clin Immunol 2012:130:382-388.e6.

7 Schulze A, van Strien RT, Praml G, et al. Characterisation of asthma among adults with and without childhood farm contact. Eur Respir 2007;29:1169-73.

8 Ernst P, Cormier Y. Relative scarcity of asthma and atopy among rural adolescents raised on a farm. Am J Respir Crit Care Med 2000;161:1563-6.

9 Merchant JA, Naleway AL, Svendsen ER, et al. Asthma and farm exposures in a cohort of rural lowa children. Environ Health Perspect 2005:113:350-6.

10 Masley ML, Semchuk KM, Senthilselvan A, et al. Health and environment of rural families: results of a Community Canvass survey in the Prairie Ecosystem Study (PECOS). J Agric Saf Health 2000;6:103-15.
11 Douwes J, Travier N, Huang K, et al. Lifelong farm exposure may strongly reduce the risk of asthma in adults. Allergy 2007;62:1158-65.

12 Timm S, Frydenberg M, Janson C, et al. The urban-rural gradient in asthma: a population-based study in Northern Europe. Int I Environ Res Public Health 2016;13:93.

13 Lawson JA, Rennie DC, Senthilselvan A, et al. Occurrence of new-onset wheeze in a 3-year follow-up study of schoolchildren. Ann Allergy Asthma Immunol 2007:99:502-8.

14 Genuneit J. Sex-Specific development of asthma differs between farm and nonfarm children: a cohort study. Am J Respir Crit Care Med 2014;190:588-90.

15 Adler A, Tager I, Quintero DR. Decreased prevalence of asthma among farm-reared children compared with those who are rural but not farm-reared. J Allergy Clin Immunol 2005;115:67-73.

16 Pekkanen J, Xu B, Järvelin MR. Gestational age and occurrence of atopy at age 31-a prospective birth cohort study in Finland. Clin Exp Allergy 2001;31:95-102.

17 Smit LAM, Zuurbier M, Doekes G, et al. Hay fever and asthma symptoms in conventional and organic farmers in The Netherlands. Occup Environ Med 2007:64:101-7.

18 Leynaert B, Neukirch C, Jarvis D, et al. Does living on a farm during childhood protect against asthma allergic rhinitis, and atopy in adulthood? Am J Respir Crit Care Med 2001;164:1829-34.

19 Bråbäck L, Hjern A, Rasmussen F. Trends in asthma, allergic rhinitis and eczema among Swedish conscripts from farming and non-farming environments. A nationwide study over three decades. Clin Exp Allergy 2004;34:38-43.

20 Braun-Fahrländer C, Gassner M, Grize L, et al. Prevalence of hay fever and allergic sensitization in farmer's children and their peers living in the same rura community. SCARPOL team. Swiss Study on Childhood Allergy and Respiratory Symptoms with Respect to Air Pollution. Clin Exp Allergy 1999;29:28-34.

21 Von Ehrenstein OS, Von Mutius E, Illi S, et al. Reduced risk of hay fever and asthma among children of farmers. Clin Exp Allergy 2000;30:187-93.

22 Sozańska B, Błaszczyk M, Pearce N, et al. Atopy and allergic respiratory disease in rural Poland before and after accession to the European Union. J Allergy Clin Immunol 2014:133:1347-53.

23 Stein MM, Hrusch CL, Gozdz J, et al. Innate immunity and asthma risk in Amish and Hutterite farm children. N Engl J Med 2016;375:411-21. 


\section{Correction: Do farm-grown lungs breathe better?}

Genuneit J, von Mutius E. Do farm-grown lungs breathe better? Thorax 2017;72:202-3.

The authors include the additional Conflicts of Interest for their article:

Erika von Mutius is listed as inventor on the following patents:

- Publication number EP 1411977: Composition containing bacterial antigens used for the prophylaxis and the treatment of allergic diseases.

- Publication number EP1637147: Stable dust extract for allergy protection

- Publication number EP 1964570: Pharmaceutical compound to protect against allergies and inflammatory diseases

Erika von Mutius is listed as inventor and has received royalties on the following patent:

- Publication number EP2361632: Specific environmental bacteria for the protection from and/or the treatment of allergic, chronic inflammatory and/or autoimmune disorders.

C Author(s) (or their employer(s)) 2019. No commercial re-use. See rights and permissions. Published by BMJ.

Thorax 2019;74:924. doi:10.1136/thoraxjnl-2016-209280corr1

Check for updates 